\title{
An Empirical Analysis of What Counts as Attributes for Vocational Technical Educational Leaders in Ghana
}

\author{
Christina Boateng
}

Employment Counselling Unit, Saskatoon Open Door Society, Saskatoon, Canada

\begin{abstract}
Effective leaders are needed to manage vocational technical educational institutions in Ghana as government plans to raise the skill level of its workforce. Leadership development programmes need to be designed for the preparation and in-service training of vocational technical leaders. This study aimed at identifying what leadership attributes need to be developed in vocational technical institutional leaders and what learning activities need to be incorporated into training programs for these leaders. The study revealed that vocational technical leaders demonstrated managerial skills more often than they do demonstrate social skill and leadership skills. They also demonstrated attributes such as energetic, achievement-oriented, accepting responsibility, insightfulness, networking, influencing, and intelligent with practical judgement more often than they do demonstrate attributes such team building, openness, motivating others, tolerance, conflict management, and sensitivity. It is therefore recommended that the Leadership Attributes Inventory (LAI) be utilized concurrence with traditional evaluation tools for potential candidates for vocational technical institution leaders. Any curriculum designed for leadership development of vocational technical educational leaders should be measured against the attributes identified by the Leadership Attributes Inventory to ensure that they addressed the development of needed attributes.
\end{abstract}

Keywords Leadership, Effective Leadership, Leadership Attributes, Leadership Development, Vocational Technical Education, Leadership Attributes Inventory

\section{Introduction}

Vocational and technical education in Ghana is changing in terms of structures, programs, processes, and practices in order to improve the quality of learning outcomes and to ensure that it is close and relevant for today's world of work. The Vocational Technical Education system therefore must respond appropriately to these changes in order to prepare individuals to be able to take advantage of the opportunities presented. In this regard, leadership becomes an important variable that must be considered critically. As[1] stated, at a time of rapid change, the need for institutional leaders who can give a public accounting of their institution is crucial. Their role will be pivotal to the successes or failures of the institutions fulfilling their missions and expanded scope of responsibilities being assigned. Effective leadership therefore becomes a vital issue if vocational and technical education in Ghana is to adapt constructively to contemporary challenges.

Reference[2] stated that an effective leader must have a combination of many skills, and the ability to create an environment where achievement is most probable. Reference

* Corresponding author:

ceboateng@gmail.com (Christina Boateng)

Published online at http://journal.sapub.org/edu

Copyright $(\underset{2}{ } 2012$ Scientific \& Academic Publishing. All Rights Reserved
[3] found out that there are certain attributes common to successful and effective leaders. Attributes are characteristics, knowledge, skills, values and competencies. These when present, act as predispositions, facilitators, and constraints, which predispose and shape leadership behaviours in consistent ways. Attributes common to successful leaders have also been found to significantly increase by a reasonable amount of planned educational experiences and training[4].

In recognition of the need for effective leadership in vocational and technical education in America, the National Centre for Research in Vocational Education was set up to provide leadership development services to vocational educators[5]. The long-range goal was to increase the number and quality of leaders to meet the challenges facing vocational and technical education in America. However, in Ghana, the means by which educators are trained and in serviced is ill suited for the development of effective and efficient leadership to meet the challenges that the sector is facing today. Currently at the highest level of training for vocational and technical educators in Ghana, the emphasis is on the acquisition of professional teaching skills. There are no organized training or learning situations and activities to enable vocational and technical educators to acquire leadership skills and competencies and to develop the attributes needed to effectively lead. The selection of leaders for vocational and technical institutions is generally based on tra- 
ditional criteria such as number of years of teaching, educational background and educational level. No attention is focused on the leadership qualities that the individual possesses or even the type of preparatory training an individual has. Experienced teachers, instructors and other educational workers are appointed to school leadership positions without any specific leadership training. It is therefore no surprise that in Ghana's Educational Strategic Plan, 2003-2015, the Government identified the need to improve upon the competencies of all heads of institutions in the educational system and has plans to institute systematic management training programs for all in order to improve their effectiveness and efficiency[6]. With increasing need for the preparation of effective and efficient leaders in the educational system including the vocational technical sub-system, there is an urgent need for diagnostic information on leadership roles and responsibilities, and leadership attributes of leaders of vocational technical education institutions to form the basis for the development of leadership training programs. The purpose of this study is to identify what leadership attributes are to be developed in vocational technical institution leaders and what learning activities need to be incorporated into the training program for these leaders.

\section{Vocational Technical Education in Ghana}

Vocational technical education had been emphasized in Ghana's education system since the colonial era. It is organized at all the three levels of education in the country: Basic or primary level, secondary level, and tertiary level. At the basic school level the focus is on exposing pupils to a range of practical activities in the vocational field in order to make them familiar with, and stimulate their interest in vocational subjects as well as provide equal opportunity for pupils to choose their future careers in either the vocational technical or general field.

At the secondary level, training is vocational in nature and aims at equipping young men and women with relevant productive skills training that will enable them fulfill the country's manpower needs in the field of technology, industry, commerce, agriculture, and business. Vocational technical education at the tertiary level is technical in nature and focuses on providing personnel with the technical knowledge and vocational skills to match the demand of skilled labor necessary for agricultural, industrial, commercial, scientific, technological, and economic development; while at the same time, paying attention to environmental issues. It occurs in the Universities, Polytechnics, and other post-secondary pre-service training institutions in the country.

Vocational technical education in Ghana faces a lot of challenges as in other countries. In 2007, the Government of Ghana commissioned a body to review the general educational system. The committee reported there has been a complete neglect of the vocational technical education sub-sector resulting in poor condition of the infrastructure and training facilities of the institutions, inadequate number of institutions, and outdated training content. Consequently, the quantity and quality of the stock of trained national workforce have been affected. The committee also found out that while the government manages and resources 500 and over senior high schools in the country, only 21 technical and 29 vocational institutions are managed and resourced by both the Ministry of Education and the Ministry of Manpower Development and Employment, the two main bodies responsible for education and training in the country. The report further mentioned that in spite of the fact that vocational technical education is considered more expensive as compared to general education, the Ministry of Education spends only one percent of its annual budget, and the Ministry of Manpower Development and Employments spends $12 \%$ of its budget on vocational technical education sub-sector. The government has no significant involvement in apprenticeship training either[6].

Another challenge facing vocational technical education in Ghana is perception that it is a route for those who are not able to function within an academic setting; this perception is compounded by a lack of progression routes from vocational technical education into higher education. In fact this negative perceptions are not limited to those who have little understanding of vocational education. In 2002, a survey of public Technical Vocational Education and Training (TVET) teachers found that none of the 87 respondents wanted their own children to study TVET programs [7].

Aside inadequate financing and negative perceptions, the socio-economic environment and the contextual framework within which vocational education is delivered in Ghana is characterized in general by other factors such as huge numbers of poorly educated, unskilled and unemployed youth, uncoordinated, unregulated and fragmented delivery systems, low quality gender and economic inequities, weak monitoring and evaluation mechanisms, and poor management and ill-adapted organizational structures [8].

The government of Ghana recognizes vocational technical education as crucial to the economic and social development of the country. In view of this, the government has identified numerous strategies to be undertaken to ensure the viability of vocational technical education in the country. Notable among these strategies are:

- making a major shift in its state education policy in favor of the vocational technical education, in order to build the nation's stock of human capital and give employable skills to the numerous youth all over the country

- reviewing and updating programs to bring them in line with modern trends and practices in industry to make vocational technical education demand-driven and relevant to the needs of Ghanaian industries

- establishing a National Apprentice-Training Board with membership from various sectors of the economy, to regulate apprentice-training in terms of registration of apprenticeship providers, content, duration of training programs, and certification 
- establishing a National Council for Technical and Vocational Education and Training to co-ordinate pre-tertiary vocational technical education in the country

- improving the linkage that exists between vocational technical institutions and industries in order to bring training more in line with the requirements of national industry and commerce

- strengthening leadership and management capacity at both national and institutional levels[6].

From the above, one can infer that leadership should be Ghana's main priority to developing and revitalizing vocational technical education. With effective and efficient leadership, the right policies could be formulated, relevant goals could be set, strategic programs could be implemented, and effective measure could be put in place to monitor and evaluate programs to ensure that expected goals achieved.

\section{Theoretical Framework of the Study}

The belief that leadership is the predominate factor in the success of educational organizations permeates the literature related to educational effectiveness[9]. Reference[10] in a review of educational leadership literature stated that educational administration is abound with definitions of leadership, descriptions of the specific components of leadership, and studies that bridge theoretical models with the practice of leadership. However, the framework for this study was a research conducted by Moss and others in the field of career and technical education leadership through the National Center for Research in Vocational Education (NCRVE), and their development of the Leadership Attributes Inventory (LAI) for identifying and measuring leadership attributes[5]. The perspective of the NCRVE conceptualisation on leadership behaviour was that, as vocational technical education leaders attempt to achieve the six major tasks of their leadership, their specific behaviours within the organization are determined by their own attributes, interacting with their perception of the group members' attributes, the groups' culture, the particular task at hand, and the general context in which the organization is operating. It states that within the constraint of a given situation, attributes, acting as predispositions, dis-inhibitors, and abilities, predispose individuals to behave in consistent ways. These attributes will remain constant across situations to influence behaviour in a wide range of tasks, groups, and contexts. After reviewing a number of researches and publications[11] assembled 37 attributes that are hypothesised to predispose the behaviour that will achieve the six broad tasks of leaders in vocational technical education. The measure of how much of each of these attributes an individual possesses and exhibits is called the leadership attribute index (LAI). The conceptualisation assumes that the amount of each attribute possessed by individuals is normally distributed in the population of vocational technical educators. The conceptualisation agreed with Lord, De Vader and Alliger[4] that there are significant and consistent relationship between personality factors and intelligence, and emergence of leadership. Therefore, it can be presumed that there are some attributes, which, if possessed in adequate amount, will increase the likelihood that desired behaviour would occur within a limited general context, such as vocational technical education.

Since then several studies have been conducted to verify the relationship between leadership attributes posited in the conceptualisation and the perceived leadership effectiveness of vocational technical administrators. Reference[12] conducted a study to examine the relationship between leadership attributes, behaviour and effectiveness of principals of private vocational high schools in Taiwan using the LAI. The result showed that all 37 leadership attributes were strongly and significantly related to perceived overall leader effectiveness. Reference[13] also conducted a study on the relationship between leader attributes and effectiveness using full-time employees of 34 post-secondary technical colleges in Minnesota. The LAI again measured a strong relationship between leader attributes and perceived effectiveness. This study further revealed that six of the attributes: motivating others, team building, adaptable, gathering and managing information, willing to accept responsibilities, and insightful were particularly useful in predicting perceived effectiveness. Another study to determine what leadership attributes were reflective of success of vocational administrators in the performance of their leadership roles was conducted by[14]. The researchers selected six states in the United State of America where secondary and post- secondary vocational education had a well-developed system. Of the 37 leadership attributes examined in the study, communication skills were found to be very important to the leadership role of successful vocational administrators. It was found out that communication skills supported and enhanced the leaders' involvement in areas such as decision-making, information gathering and management, team building, sensitivity and respect, and, conflict management. The study also showed that the 37 leadership attributes could be clustered in three categories of social skills and characteristics, personal characteristics and managerial skills. And that, even though all the three categories are important, those that fall within social skills and characteristics are essential for projecting personal characteristics and managerial skills.

NCRVE also conceived that leadership development in vocational technical education should aim at deliberately attempting to effect positive change in selected attributes to increase the likelihood that vocational technical administrators will perceive opportunities to behave as leaders, grasp those opportunities, and succeed in achieving the tasks of leaders in a wide variety of situations and professional roles. By so doing, the conceptualisation agreed with studies by[15-17] that some of the 37 attributes common to successful leaders can be increased by a reasonable amount of planned educational experience while some may be resistant to improvement. Based on this conception,[18] concluded that leadership development activities must aim at improving 
those leadership attributes that prove to be susceptible to change by educational interventions and those attributes that prove resistant to change might provide a basis for selection. In so doing, vocational technical educators will be able to increase the number and quality of leaders prepared to meet present and future challenges facing the field.

\section{Methodology}

A cross-sectional descriptive survey design was the method used for the study. The reasons for the choice were that, the researcher was interested in revealing the perceptions of staff about how principals in vocational technical institutions behave and perform as leaders and what attributes can be associated with their behaviors. The descriptive survey method was appropriate for this topic in the sense that it enabled the researcher to describe the leadership situation within the institutions as it pertains now from the perspective of the followers whose attitudes are as important as the actual tasks completed by the leaders. The assumption here was that, since leadership cannot exist in the absence of followers, the views of the followers are a proper way of assessing the leadership effectiveness of the leaders.

A total of 284 individuals were sampled from the population for the study using the stratified random sampling method. The population was composed of all staff of the ten polytechnic institutions in Ghana. This sample consisted of 197 academic staff and 87 administrative staff members. The Leader Attributes Inventory (LAI), created by Moss and others in 1988 and updated in 1994 was used for the study. The LAI has 37 items, each, consisting of the name and a brief description of an attribute. These are managerial, personal, and social skills that are most likely to predispose desirable leadership behaviour. Respondents were to assess the vocational technical institution principals on a sevenpoint scale that indicated the frequency with which an attribute specified accurately described the principal. The rating scale ranges were: forty percent or less of the time (0); fifty percent of the time (1); sixty percent of the time (2); seventy percent of the time (3); eighty percent of the time (4); ninety percent of the time (5) to one hundred percent of the time (6). The mailed survey was adopted to collect responses for the study.

Two hundred and forty-two responses were received and analysed using descriptive statistics. The mean and standard deviation for all the 37 leadership attributes items were computed. Again, numerical mean differences were computed between the means of full-time staff and part-time staff; less experienced and more experienced vocational educators; staff with leadership responsibilities and staff with no leadership responsibilities; academic and administrative staff; and staff with personal leadership aspirations and staff with no leadership aspirations.

\section{Results and Discussions}

The results showed the means ratings of the principals on all the 37 attributes ranged from a low of 2.07 (approximately 60 percent of the time) to a high of 4.89 (approximately 90 percent of the time). The highest rated attribute was accepting responsibility while the least rated attribute was tolerant of frustrations. None of the leadership attributes was rated above 90 percent of the time ( $\mathrm{M}>5.00)$. Overall, the respondents perceived their principals as demonstrating six out of the 37 attributes above 80 percent of the time, that is, $M>4.00$. These attributes were energetic, insightful, achievement oriented, initiating, accepting responsibility, and intelligent with practical judgement. The least demonstrated leadership attributes as shown by the results were adaptability (open to change), tolerant of ambiguity and complexity, tolerant of frustrations, even disposition, motivating others, planning, delegating, team building, coaching, and conflict management. These ten attributes were rated below 70 percent of the time $(\mathrm{M}<3.00)$. The rest of the attributes were rated between 3.00 and 4.00 . This results revealed that of the six leadership attributes which [13] found to be useful in predicting leadership effectiveness (motivating others, team building, adaptable, gathering and managing information, willing to accept responsibility, insightful), only willing to accept responsibility and insightful were perceived to be shown by the principals above $80 \%$ of the time. These two showed mean scores of 4.89 and 4.64 respectively. Adaptability, team building, and motivating others were found to be part of the least demonstrated attributes. Communication skills, found to be an important attribute[15] because of its involvement with other attributes, had a mean score of 3.31. This means that the principals exhibited good communicative skills above 70 percent of the time.

The responses of the following groups were compared: academic staff and administrative staff, staff with leadership responsibilities and staff without any leadership responsibilities, full- time staff and part-time staff, more experienced and less experienced vocational educators, staff with personal leadership aspiration and staff with no leadership aspirations. This was to find out their agreements and disagreements in terms the attributes that the principals demonstrated in their roles as leaders.

Generally, the administrative staff perceived the principals as exhibiting 28 of the 37 attributes more often than the academic staff perceived them. The responses of administrative staff showed a highest mean of $\mathrm{M}=5.67, \mathrm{SD}=1.45$, while the responses of academic staff showed a highest mean of $\mathrm{M}=4.39, \mathrm{SD}=1.22$. Again, while the administrative staff rated the principals highest on the attribute, energetic with stamina, the academic staff rated their principals highest on the attributes, achievement-oriented. Apart from this difference, the two groups also disagreed on the attribute that is least exhibited by their principals. To the administrative staff, the principals do worst on the attribute of tolerating frustrations. They exhibit this about $65 \%$ of the time $(\mathrm{M}=2.97$, SD 
$=1.87)$. But to the academic staff, the principals do worst on the attribute of team building $(\mathrm{M}=1.67, \mathrm{SD}=.89)$ : They exhibit this attribute $55 \%$ of the time. The greatest amount of disagreement between the two groups with respect to their views on what attributes principals exhibited in their leadership roles and performance though, occurred in the following attributes: time management, problem solving, coaching, and appropriate use of leadership style. On all these four attributes, the result showed a difference of more than 2.0 between the mean scores of academic and administrative staff.

In spite of all these differences, the result showed that there was some agreement between the perception of the administrative staff and the academic staff on what leadership attributes the principals exhibited in their roles as leaders of their institutions. The views of both the administrative and academic staff on how often the principals exhibited attributes such as energetic, insightful, networking, adaptable or open to change, intelligent with practical judgement, and ethical were almost the same. On all six attributes, differences between the mean scores of the two groups were minimal (less than 1.0).

In comparing the mean responses between full-time staff and part- time staff, it was evident that full-time staff and part-time staff have different perception on how often principals exhibited which leadership attribute. The result showed that the mean scores of full-time staff on how often principals exhibited leadership attributes were higher in the case of 30 attributes out of the 37 attributes as compared to that of part-time staff. The full-time staff rated attributes such as willingness to accept responsibility, organising, and networking, highest; but part-time staff rated ethical standards, achievement-oriented, and initiating highest. On the other hand, both groups rated tolerant of ambiguity and complexity; and adaptability as the attributes that is exhibited by the principals the least. The greatest disagreement was observed in their ratings on four leadership attributes: sensitivity, conflict management, adaptability, and team building. The mean differences between the responses of the two groups were $2.28,2.07,2.03$, and 1.98 respectively. However, the greatest amount of agreement between the perception of the full-time and part-time staff was observed in their responses for leadership attributes such as networking, energetic, and insightful, where the differences between the mean score of the two groups were less than 1.00.

When the responses of staff with leadership responsibilities and those with no leadership responsibilities in the institutions were compared, differences in perceptions were again observed. The differences were however, limited to those attributes that both group perceived the principals to exhibit the least. The responses of staff with leadership responsibilities showed that attributes such as delegating, coaching, conflict management, and team building were exhibited least by the principals. The mean score for these attributes were below $2.00(\mathrm{M}<2.00)$. The responses of staff with no leadership responsibilities on the other hand, showed that motivating others, team building, and conflict man- agement are attributes that were exhibited least of the time. The means scores for these were also below $2.0(\mathrm{M}<2.0)$. This shows that while the two groups agreed on how often principals exhibited attributes such as conflict management and team building, they disagreed on how often principals exhibited attributes such as coaching, delegating, and motivating others. The analysis also showed that the mean differences between the perceptions of the two groups on all the attributes were low, ranging from 0.22 to 1.87 . The greatest difference was found in their responses on the attribute, delegating, where there was a mean difference of 1.87 between the two groups while the greatest agreement was found on their responses on the attribute, conflict management. The mean difference in this case was as low as 0.22 .

While differences among staff with leadership responsibilities and staff with no leadership responsibilities on how often principals exhibited certain leadership attributes were not large, the result showed larger differences among more experienced vocational educators and less experienced vocational educators. The mean differences between the views of more experienced vocational educators and less experienced vocational educators ranged from 0.98 to 2.97 . The highest mean difference of 2.97 was found in the views of more experienced vocational educators and less experience vocational educators on how often principals used appropriate leadership styles; the least mean difference of 0.98 between the views of these same groups was found in how often the principals motivated others to perform. The result further showed that more experienced vocational educators generally perceived the principals to exhibit most of the attribute less often than less experienced vocational educators perceived them to have done.

The responses of staff with personal leadership aspiration and those with no leadership aspiration were also compared. The result revealed that staff with leadership aspiration perceived the principals to demonstrate five of the attribute less that $60 \%$ of the time. These attributes were information management, ideologically beliefs compatible with the belief of the group, appropriate use of leadership styles, communication skills and sensitivity. Staff with no leadership aspiration on the other hand, perceived the principals to demonstrate only two of the attribute less that $60 \%$ of the time. These were communication and tolerance of frustration. Another significant difference between the responses of these two groups was their perception on how the principals demonstrated initiative taking and visionary. Staff with personal leadership aspirations viewed the principals to be less visionary and initiative takers. The mean differences between staff with leadership aspirations and staff with no leadership aspiration on the two attributes of initiative taking and visionary responses were 2.77 and 2.56 respectively.

\section{Conclusions and Recommendations}

Principals demonstrated attributes such as being energetic with stamina, insightfulness, and achievement oriented; 
willing to accept responsibilities, networking, and solving problems most often. When this finding is compared with leadership clusters identified by[13], one can conclude that the staff perceived the principals to demonstrate managerial skills or action-oriented and ethical competencies most often. These are skills that are always critical to one's ability to achieve business results. They are management-oriented, thus they will enable the principals to manage their institutions effectively and efficiently. On the other hand, attributes such as adaptability, open to change, tolerant of frustrations, communication, sensitivity, motivating others, and team building were found to be demonstrated less often. These are interpersonal and social skills according to Moss and Liang`s classification. These are attributes that enable a person's leadership competencies. This implies that the principals are offering more management and less leadership. There is therefore the need for principals to improve upon their interpersonal and social skills in order to offer more leadership in their institutions.

It is therefore recommended that though educational background and work experience of leadership candidates are important, selection committees should also take into consideration the presence or lack of leadership attributes in applicants seeking leadership positions in vocational technical educational institutions. The Leadership Attributes Inventory (LAI) could be utilized as an additional evaluation tool for potential candidates for vocational technical institution leaders in Ghana. Curriculum related to leadership development of vocational technical educational administrators should be measured against the attributes identified by the Leadership Attributes Inventory to ensure that all aspects are covered and addressed in any designed program.

\section{REFERENCES}

[1] Gardner, H. , "The vehicle and the vehicles of leadership", American Behavioral Scientist, 42, 1009-1023, 1999.

[2] Longenecker, C. \& Pinkel, G., "Coaching to win at work," Manage, 48, 2, 19-21, 1997.

[3] Moses, J. Jr., Finch, C., \& Johanses, B. C. , "What makes a vocational administrator an effective leader?", Journal of Industrial Teacher Education, 29(1), 1-5, 1991.

[4] Lord, R. G., Devader, C. L., \& Alliger, G. M., "A meta-analysis of the relation between personality traits and leadership perceptions: An application of validity generation procedure", Journal of Applied Psychology, 73(3), 402-410, 1989 .
[5] Moss, J., Jr., Finch, C. R., Lambrecht, J. J., \& Jensrud, Q. , "Leader Attributes Inventory manual", University of California at Berkeley, National Centre for Research in Vocational Education, 1994.

[6] Government of Ghana, "Educational strategic plan 20032015”, Ministry of Education, 2007.

[7] Anamuah-Mensah, J., "Vocational/Technological Education for Accelerated Wealth Creation: Critical Issues Facing the Nation." Paper presented at the 56th New Year School Conference organized by the Institute of Adult Education, the University of Ghana, 30 December 2004.

[8] African Union "Strategy to Revitalize Technical and Vocational Education and Training (TVET) in Africa. Paper presented at a Meeting of the Bureau of the Conference of Ministers Of Education of the African Union (COMEDAF II+) Addis Ababa, Ethiopia, 29-31 May 2007.

[9] Barker, B., "Do leaders matter?”, Educational Review, 53, 1, 65-77, 2001.

[10] Taylor, P., "Leadership in Education', Emergency Librarian, 21, 3, 9-18, 1994.

[11] Moss, J., Johansen, B-C. \& Preskill, H., "Developing the Leader Attributes Inventory: An odyssey", Journal of Industrial Teacher Education, 28, 2, 7-22 1991.

[12] Liang, M. T-L., Chiou, S-B. Liou, T-M, "The relationship between leadership attributes, behaviours and the effectiveness of principals at private vocational high schools in Taiwan”, Global Journal of Engineering Education, 5, 2, 147-152, 2001 .

[13] Moses, J. Jr., \& Liang, T., "Leadership, leadership development, and the national centre for research in vocational education", University of California at Berkeley, National Centre for Research in Vocational Education, 1990.

[14] Finch, C. R., Gregson, J. A., \& Faulkner, S. L., "Leadership behaviours of successful vocational education administrators", University of California at Berkeley, National Centre for Research in Vocational Education, 1991.

[15] Bass, B. M., Stogdill's handbook of leadership, Macmillan, New York, 1981.

[16] Yammarino, F. J. \& Bass, B. M., "Person and situation views of leadership: A multiple levels of analysis approach", Leadership Quarterly, 2, 121-139, 1991.

[17] Yukl, GA., Leadership in organizations ( $3^{\text {rd }}$ ed), Prentice Hall, Englewood Cliffs, New Jersey, 1994.

[18] Moss, J., Jr.; Leske, G. W.; Jensrud, Q.; and Berkas, T. H., "An evaluation of seventeen leadership development programs for vocational educators", Journal of Industrial Teacher Education, 32, 1, 26-48, 1994. 